\title{
Effects of Korean Medicine Health Promotion program for Children -Focus on Education and Prevention Programs- ${ }^{\dagger}$
}

\author{
Angela Dongmin Sung ${ }^{1}$, Hyun-Kyung Sung ${ }^{2}$, Haemo Park ${ }^{1}$, Sundong Lee ${ }^{1}$ \\ ${ }^{1}$ Dept. of Preventive Medicine, College of Korean Medicine, Sangji University \\ ${ }^{2}$ Dept. of Pediatric Medicine, College of Korean Medicine, Semyung University
}

\begin{abstract}
Objectives: This study was designed to confirm the effects of the Korean Medicine health promotion program targeting young children. One important aspect of the Korean Medicine health promotion program for children is to bring awareness of health benefits of introducing Korean Medicine methods to young children and to promote incorporating such methods in children's daily activities to develop healthy habits.

Methods: The following experiment was conducted for 6 weeks, and the participants were in the age between 2 to 6 years old from 6 child care centers in Wonju and Chungju. 268 participants were in the intervention group, and 277 in the control group. To measure the outcomes of the Children Korean Medicine health program, the intervention group received Korean Medicine prevention programs (children education, parent education, growth exercises, common cold prevention scarf, and pear herb tea), control group did not. This research collected and compared the following data as the children's health indicators to measure the outcomes before and after the program: medical services usage, the number of absences, early leaves, and tardiness to the child care centers due to the participant's health condition.

Results: After applying the children's health promotion programs on children between the age of 2-6, there was a decrease in the overall medical services usage, absences, early leaves, and tardiness to the child care center. This health promotion program was purely based on Korean medical theories and Korean Medicine resources without any conventional medical mediation.

Conclusions: It can be concluded that a positive change was noted in raising awareness of Korean Medicine through educating both the parents and children. By learning to incorporate Korean Medicine prevention practices to daily habits, not only was there a reduction in the Medical services usage, but the children also became familiar and comfortable with Korean Medicine and its treatment procedures; the overall satisfaction level of the program was also high.
\end{abstract}

\section{Key Words : Children, Health promotion, Korean Medicine, Child care center}

\footnotetext{
- Received : 8 December 2017 - Revised : 22 December 2017 Accepted : 22 December 2017

- Correspondence to : Sundong Lee

Department of Preventive Medicine, College of Korean Medicine, Sangji University

Sangjidae-gil 83, Wonju, Gangwondo, 26389, Republic of Korea

Tel : +82-33-730-0665, Fax : +82-33-730-0653, E-mail : sdlee@sangji.ac.kr

- Correspondence to : Haemo Park

Department of Preventive Medicine, College of Korean Medicine, Sangji University

Sangjidae-gil 83, Wonju, Gangwondo, 26389, Republic of Korea

Tel : +82-33-738-7508, Fax : +82-33-730-0653, E-mail : haemopark@sangji.ac.kr

$\dagger$ This following paper took parts of Ministry of Health and Welfare "2016 Korean Medicine Health Promotion program for Children" written by the same authors and edited and added parts of it.
} 


\section{Introduction}

The period of early childhood is a time where constant growth and development occurs. As interactions becomes more active, a number of sensory organs develop allowing the body to learn and accept many new things ${ }^{1,2)}$. The health developed during this period is important as it becomes fundamental for adulthood, and early intervention in a child's health is crucial as children's health heavily depends on the quality of 'care' at the time. Although parents in the modern society can easily get access to child care information, it is relatively difficult to find the exact information they need for their children. Therefore, demand for health promotion programs for children and professional trust-worthy information that parents can access is becoming higher ${ }^{3,4)}$.

Public health programs for Korean medicine first started as a demonstration project in $1990^{5,6}$, and in 2002, as public Korean medical doctors started to get allocated in public health centers, Korean medical health services expanded its territory. From 2003, 8 fundamental programs such as stroke prevention, child care, pregnant mothers, qigong exercises, and Sasang constitution and selectional programs demanded by the local communities were applied in national health centers. It got to a point where these programs were conducted in 177 places nationwide in $2005^{7-8)}$. In 2013, Korean health promotion program was integrated and became a Community Health Promotion Program, and due to this integration, the program was re-structured differentiated by different life cycle stages. During this process, the demand from local communities, priorities in health policies, grounds for business, and possibility of realization became important, and at the same time, the importance of standardized programs and evaluation methods started to get stressed $^{6-11)}$.

Since 2013, as part of the overall health promotion program for local communities, Korean medical health promotion program differentiated by life cycle stages were provided. A total of 132 health centers ran Korean medical health promotion programs and program contents included Korean medicine care $(36.7 \%)$, Korean medical treatment (30.1\%), qigong exercises (15.1\%), and body activities $(6.1 \%)^{12)}$. Since 2015 , Korean medical services are being provided with the aim of improving the health of young children, children and teenagers, pregnant woman, adults, and elderly people from the vulnerable social group ${ }^{13)}$.

As the modern society is facing problems of low fertility rates and population aging, the importance of health promotion programs for pregnant woman and children have been continuously emphasized. However, according to satisfactory surveys conducted on those who participated in Korean medical health promotion programs, the demand for young children programs were relatively low with $11.4 \%$, and as for the programs wished by the program manager, young children's category was relatively low with $17.1 \%{ }^{14,15)}$. These results were indications that young children's program were not being applied enough in real life situations compared to its importance. In particular, only 4 health centers of the health promotion program out of 18 were running programs for children of preschool age (aged 2-6) ${ }^{16-18)}$. The reasons that had been pointed out for this was lack of manuals for standardized programs and lack of research in the evaluation of effects ${ }^{6}$.

Therefore, the following research aims to analyze the effects of the Korean medical health promotion program for children which was conducted to increase awareness and practice of Korean medical health care methods and to satisfy the needs of local communities. Furthermore, the study aims to provide baseline data based on the following program. 


\section{Study material and method}

\section{Subject of Study, Study Period, and Classification}

The study was conducted on children (aged 2-6) that attend child care center at Wonju, Gangwon-do Province and Chungju, Chungcheongbuk-do Province. Information on the size of child care centers and number of students were collected through child-care statistics, and with the agreement of the child care center director, an MOU (memorandum of understanding) was signed before conducting the study. For the both the control group and intervention group, two child care centers at Wonju (government owned), and a child care center in
Chungju (privately owned) were selected for the 6 week program. In the case of the control group, a child care center that had a similar size with the intervention group child care center was chosen and were not put in any type of program. The study was conducted for 6 weeks, from the $19^{\text {th }}$ of September 2016 until the $28^{\text {th }}$ of October 2016 (Table 1, Figure 1).

\section{Composition of Research Program}

The Korean medicine health promotion program was composed of three subjects, the children (aged 2-6), parents, and the teachers. The teachers were asked to participate in the education program for parents, and therefore the following research was focused around the children and parents (Figure 2).

Table 1. The Characteristics and Classification of Participating Child Care Centers.

N: Person (\%)

\begin{tabular}{|c|c|c|c|c|c|c|}
\hline \multirow{2}{*}{$\begin{array}{l}\text { Classification } \\
\text { Child care centers }\end{array}$} & \multicolumn{3}{|c|}{ Intervention group $(\mathrm{n}=363)$} & \multicolumn{3}{|c|}{ Control group $(n=347)$} \\
\hline & $\mathrm{U}$ & W & $\mathrm{H}$ & $\mathrm{T}$ & $\mathrm{S}$ & $\mathrm{R}$ \\
\hline Location & Wonju & Wonju & Chungju & Wonju & Wonju & Chungju \\
\hline Type & public & public & private & public & public & private \\
\hline Total number of children & 97 & 127 & 139 & 119 & 100 & 128 \\
\hline No. of participants & $68(70.1)$ & $79(62.2)$ & $121(87.1)$ & $81(68.1)$ & $84(84.0)$ & $112(87.5)$ \\
\hline
\end{tabular}

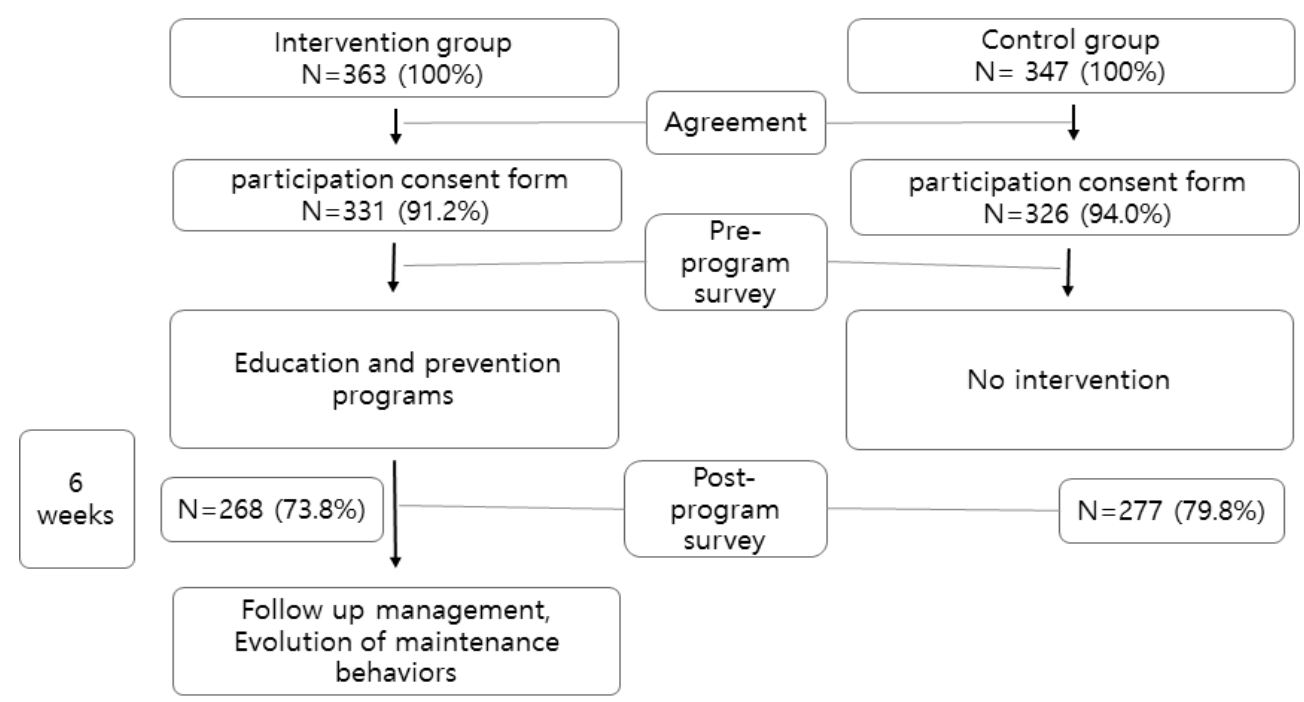

Fig. 1. Flow chart of study 


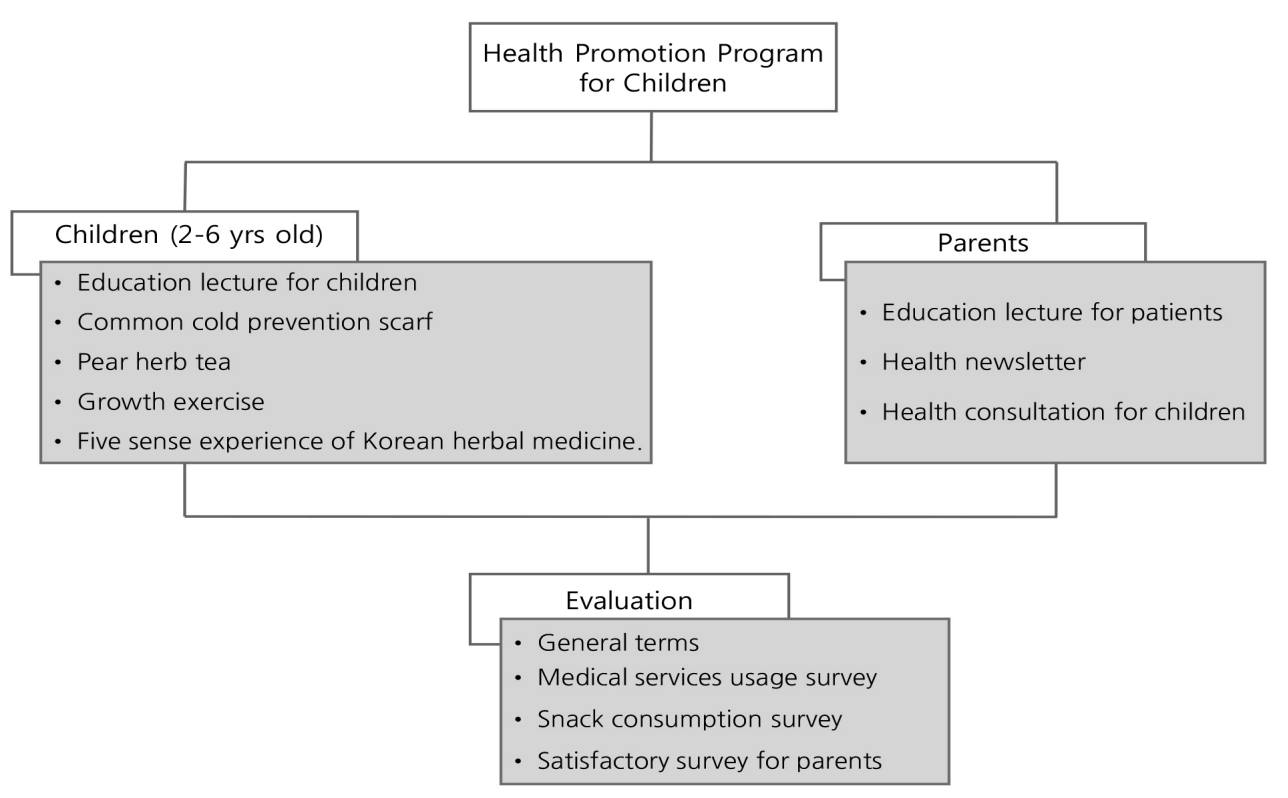

Fig. 2. Process of the program

For the children, activity based programs such as five sense experience of Korean medicine- the five senses are involved and participate in the experience. Specifically, the three senses like sight, smell and touch of herbal medicine. For other activities, children were asked to conduct growth exercises composed of 16 moves more than once a day. They were also asked to put on scarfs on their way to child care center and back home so that the body can adapt to outside temperature change. In addition, pear herb tea were given to children as snacks and were asked to be consumed two times per week. For the parents, 3 education and consultation sessions were run by Korean medical pediatricians from Korean medical universities and part time doctors from Korean medical institutions near the area. There were a total of 7 different subjects in the sessions including the characteristics of young children, children that are weak in the five viscera organs, taking care of a young child's body, respiratory diseases on children, digestive system diseases, nerve system diseases, allergy related diseases, and children's growth and obesity related problems. For those parents who could not take part in the education session, a booklet with all the outlining information were sent and the sessions were recorded so that they can view it through the internet.

\section{The evaluation period of research and content}

The evaluation content and time of evaluation differed for both the controlled and intervention group. For the intervention group, the pre-evaluation content included general matters, the medical use of children, children that are weak in the five viscera organs, snacks, child-care knowledge in Korean medicine, practical use of Korean medical health, and the satisfactory level of parent's program. For the controlled group's pre-evaluation content, there were categories included general matters, medical use of children, snacks, child-care knowledge in Korean medicine, and practical use of Korean 
medical health. In the case of after evaluation contents, all the categories excluding general matter were once again evaluated.

\section{Statistical Analysis}

The statistical analysis for the following method was conducted utilizing the SPSS (ver.23) and SAS (ver. 9.4) program, and the general characteristics of the research subject was done through frequency and cross analysis, and for analyzing medical use before and after conducting the program, the standard t-test was conducted. To compare the difference of medical use, absence, early leave, and late attendance of children before and after the intervention, the Wilcoxon signed rank test and Mann-Whitney $U$ test were conducted. To understand the net effects of the variables related to double differences, a double difference analysis was conducted utilizing a zero inflated negative binomial regression model of before and after applying the control variable. Furthermore a linear regression model on the number of medical use, absence, early leave, and late attendance was done.

As the evaluation process for the Korean medicine health promotion program was different for the controlled group and intervention group, there were limitations of controlling variables such as sociocultural changes and economic changes that occurred during the research period when simply comparing the differences in results before and after the intervention. Therefore, there were difficulties in measuring the net effects. In order to overcome these obstacles, the difference in difference analysis which verifies the effects of a program conducted in between two time periods. The difference in difference model analysis was conducted to see the interaction effects and under the following regression equation ' $Y$ (number of medical use or absence) $=a$ $+\beta 1 \mathrm{Gi}+\beta 2 \mathrm{Ti}+\beta 3(\mathrm{Gi} \times \mathrm{Ti})+\beta 4 \mathrm{Xi}+\varepsilon^{\prime}$, the effects were aimed to be shown using the slope (influence, size, beta index) $B 3$ which indicates the effects of difference in difference. Table 3 is an indication of the difference in difference analysis suited for the following study and is a result of applying $\mathrm{Gi}$ (intervention $=1$, control $=0$ ) and $\mathrm{Ti}$ (October $=1$, September $=0$ ) in the above regression equation.

\section{Research Ethics}

The planning, agreement and survey for the following study was conducted under the approval of IRB (IRB No. SJ IRB Human-16-004) of Sang-ji University.

\section{Results}

\section{The socio-demographic characteristics} of the participating children and parents

Out of the total of 545 participants, 268 (49.2\%) were in the intervention group and $277(50.8 \%)$ were in the control group. 264 (48.5\%) were male and $280(51.5 \%)$ were female.

There were more fathers and mothers under their

Table 2. DID (difference in difference) Analysis Model

$\left(G_{i}\right.$, control=1, medicated $=0, T_{i}$ October=1, September $\left.=0\right)$

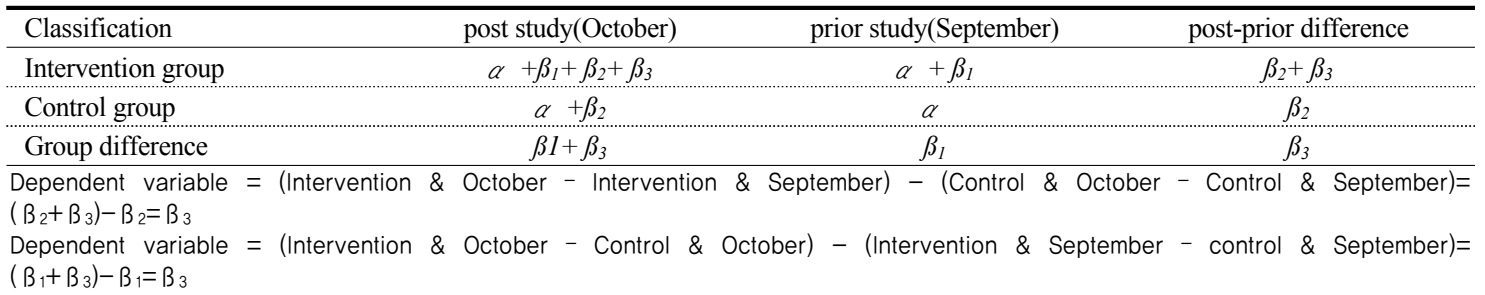


30s with $319(62.7 \%)$ fathers and $386(76.9 \%)$ mothers. Most of the parents highest level of education were bachelor degree or under with 375 (76.2\%) fathers and $374(76.2 \%)$ mothers.

The socio-demographic characteristics of the participating children and parents follow table 3 .

\section{Analysis of medical use before and after the program}

1) Matching sample t-test on the participating children

The results for the matching sample t-test on participating children follow Table 4. When looking at medical use related to respiratory diseases, the number of medical use decreased in both the controlled and intervention group. The decrease level was more significant in the intervention group. Medical use due to digestive diseases also decreased after the program in both the intervention and control group and the decrease level was more significant in the intervention group. The medical use due to otolaryngology related diseases decreased after the program in both the intervention and controlled group and the decrease level was more significant in the intervention group. When investigating the overall medical use related to overall sickness (respiratory, digestive, and otolaryngology), the numbers decreased more in the intervention group than the controlled group. Furthermore, the number of absence, early leave, and

Table 3. Sociodemographic Characteristics on the Participating Children and Parents

$\mathrm{N}:$ Person (\%)

\begin{tabular}{|c|c|c|c|c|c|}
\hline \multicolumn{2}{|l|}{ Variables } & \multirow{2}{*}{$\begin{array}{c}\text { Total } \\
545(100.0)\end{array}$} & \multirow{2}{*}{$\begin{array}{c}\begin{array}{c}\text { Intervention } \\
\text { group }\end{array} \\
268(49.2) \\
\end{array}$} & \multirow{2}{*}{$\begin{array}{c}\begin{array}{l}\text { Control } \\
\text { group }\end{array} \\
277(50.8) \\
\end{array}$} & \multirow[t]{2}{*}{$p$} \\
\hline & & & & & \\
\hline \multirow{2}{*}{ Sex } & Boy & $264(48.5)$ & $126(47.2)$ & $138(49.8)$ & \multirow{2}{*}{.299} \\
\hline & Girl & $280(51.5)$ & $141(52.8)$ & $139(50.2)$ & \\
\hline \multirow{5}{*}{ Age } & 2 & $39(7.4)$ & $15(5.6)$ & $24(9.3)$ & \multirow{5}{*}{.228} \\
\hline & 3 & $114(21.6)$ & $58(21.6)$ & $56(21.6)$ & \\
\hline & 4 & $142(26.9)$ & $67(25.0)$ & $75(29.0)$ & \\
\hline & 5 & $141(26.8)$ & $81(30.2)$ & $60(23.2)$ & \\
\hline & 6 & $91(17.3)$ & $47(17.5)$ & $44(17.0)$ & \\
\hline \multirow{2}{*}{ Sibling } & Yes & $432(83.7)$ & $215(83.3)$ & $217(84.1)$ & \multirow{2}{*}{.453} \\
\hline & No & $84(16.3$ & $43(16.7)$ & 41(15.9) & \\
\hline \multirow{3}{*}{$\begin{array}{l}\text { Child care } \\
\text { period }\end{array}$} & more than 1 year & $438(80.4)$ & $228(85.1)$ & $210(81.1)$ & \multirow{3}{*}{.455} \\
\hline & 6 month- 1year & $70(13.3)$ & $32(11.9)$ & $38(14.7)$ & \\
\hline & less than 6 month & $19(3.6)$ & $8(3.0)$ & $11(4.2)$ & \\
\hline \multirow{2}{*}{$\begin{array}{l}\text { Parenting } \\
\text { of mother }\end{array}$} & Yes & $473(86.8)$ & $230(85.8)$ & $243(87.7)$ & \multirow{2}{*}{.298} \\
\hline & No & $72(13.2)$ & $38(14.5)$ & $34(12.3)$ & \\
\hline \multirow{5}{*}{$\begin{array}{l}\text { Monthly income } \\
\text { (Won) }\end{array}$} & under 2 million & $28(6.0)$ & $15(6.0)$ & $13(5.9)$ & \multirow{5}{*}{.940} \\
\hline & 2million -3million & $92(19.6)$ & $49(19.8)$ & $43(19.5)$ & \\
\hline & 3million -4million & $133(28.4)$ & $67(27.0)$ & $66(29.9)$ & \\
\hline & 4million -5million & $96(20.5)$ & $50(20.2)$ & $46(20.8)$ & \\
\hline & Above 5million & $120(25.6)$ & $67(27.0)$ & $53(24.0)$ & \\
\hline \multirow{2}{*}{ Insurance } & Health insurance & $471(95.3)$ & $245(97.2)$ & $226(93.4)$ & \multirow{2}{*}{.034} \\
\hline & Medical care assistance & $23(4.7)$ & $7(2.8)$ & $16(6.6)$ & \\
\hline \multirow{2}{*}{ Father's age } & Less than 30 & $319(62.7)$ & $164(63.6)$ & $155(61.8)$ & \multirow{2}{*}{.370} \\
\hline & 30 and more & $190(37.3)$ & $94(36.4)$ & $96(38.2)$ & \\
\hline \multirow{2}{*}{ Mother's age } & Less than 30 & $386(76.9)$ & $201(77.9)$ & $185(75.8)$ & \multirow{2}{*}{.327} \\
\hline & 30 and more & $116(23.1)$ & $57(22.1)$ & $59(24.2)$ & \\
\hline
\end{tabular}


tardiness decreased more in the intervention group. The difference in medical use due to overall sickness (respiratory, digestive, and otolaryngology) and difference in number of absence, early leave, and tardiness has been shown through diagrams.

2) The medical use and number of absence, early leave, and tardiness of participating children

Table 4. Matching Sample t-test on the Participating Children

\begin{tabular}{|c|c|c|c|c|c|c|c|}
\hline & & \multicolumn{3}{|c|}{ Intervention } & \multicolumn{3}{|c|}{ Control } \\
\hline & & pre & post & $p^{2)}$ & pre & post & $p^{2)}$ \\
\hline \multirow{2}{*}{ Respiratory } & outpatient & $1.67 \pm 2.54$ & $1.47 \pm 2.42$ & 0.261 & $1.58 \pm 2.58$ & $1.55 \pm 3.11$ & 0.876 \\
\hline & Medical usage ${ }^{1)}$ & $1.71 \pm 2.76$ & $1.46 \pm 2.43$ & 0.213 & $1.60 \pm 2.66$ & $1.56 \pm 3.15$ & 0.836 \\
\hline \multirow{2}{*}{ Digestive } & outpatient & $0.17 \pm 1.30$ & $0.02 \pm 0.21$ & 0.072 & $0.19 \pm 0.80$ & $0.14 \pm 0.68$ & 0.190 \\
\hline & Medical usage & $0.17 \pm 1.31$ & $0.02 \pm 0.21$ & 0.067 & $0.20 \pm 0.82$ & $0.14 \pm 0.69$ & 0.162 \\
\hline \multirow{2}{*}{ Otolaryngology } & outpatient & $0.51 \pm 1.82$ & $0.44 \pm 2.02$ & 0.604 & $0.39 \pm 1.11$ & $0.29 \pm 1.24$ & 0.307 \\
\hline & Medical usage & $0.51 \pm 1.82$ & $0.44 \pm 2.02$ & 0.621 & $0.40 \pm 1.12$ & $0.29 \pm 1.24$ & 0.274 \\
\hline \multicolumn{2}{|c|}{ Total Medical utilization } & $2.40 \pm 3.90$ & $1.92 \pm 4.04$ & 0.120 & $2.20 \pm 3.38$ & $1.98 \pm 4.03$ & 0.392 \\
\hline \multicolumn{2}{|l|}{ Absence } & $0.59 \pm 1.58$ & $0.43 \pm 1.31$ & 0.164 & $0.53 \pm 1.38$ & $0.49 \pm 1.74$ & 0.769 \\
\hline \multicolumn{2}{|c|}{ Early leave tardiness } & $0.19 \pm 0.59$ & $0.15 \pm 0.62$ & 0.378 & $0.17 \pm 0.45$ & $0.20 \pm 0.75$ & 0.587 \\
\hline \multicolumn{2}{|c|}{ Total absence, early leave and tardiness } & $0.78 \pm 1.84$ & $0.57 \pm 1.59$ & 0.139 & $0.69 \pm 1.55$ & $0.68 \pm 1.99$ & 0.937 \\
\hline
\end{tabular}

1) Medical usage (Medical services usage): days of medical treatment and hospitalization added

2) $p$-value by paired t-test

Table 5. Medical Services Usage and Days of Absence, Early Leave and Tardiness before and after the Mediation for Participating Children

\begin{tabular}{|c|c|c|c|c|c|c|}
\hline & & & \multicolumn{2}{|c|}{ Interventional trial $^{1)}$} & \multirow{2}{*}{$\begin{array}{c}\text { Difference between } \\
\text { pre and post }\end{array}$} & \multirow{2}{*}{$p$-value ${ }^{2)}$} \\
\hline & & & pre (Sep) & post (Oct) & & \\
\hline \multirow{16}{*}{$\begin{array}{l}\text { Medical } \\
\text { services } \\
\text { usage }\end{array}$} & \multirow{4}{*}{ Respiratory } & Intervention & $1.71 \pm 2.8$ & $1.46 \pm 2.4$ & -0.25 & 0.183 \\
\hline & & Control & $1.60 \pm 2.7$ & $1.58 \pm 3.2$ & -0.02 & 0.386 \\
\hline & & Between group difference & 0.11 & -0.12 & -0.23 & \\
\hline & & $p$-value ${ }^{3)}$ & 0.364 & 0.302 & & \\
\hline & \multirow{4}{*}{ Digestive } & Intervention & $0.17 \pm 1.3$ & $0.02 \pm 0.2$ & -0.15 & $0.010^{*}$ \\
\hline & & Control & $0.20 \pm 0.8$ & $0.13 \pm 0.7$ & -0.07 & 0.186 \\
\hline & & Between group difference & -0.03 & -0.11 & -0.08 & \\
\hline & & $p$-value ${ }^{3)}$ & 0.246 & $0.005^{*}$ & & \\
\hline & \multirow{4}{*}{ Otolaryngology } & Intervention & $0.51 \pm 1.8$ & $0.44 \pm 2.0$ & -0.07 & 0.106 \\
\hline & & Control & $0.40 \pm 1.1$ & $0.27 \pm 1.2$ & -0.13 & $0.035^{*}$ \\
\hline & & Between group difference & 0.11 & 0.17 & 0.06 & \\
\hline & & $p$-value ${ }^{3)}$ & 0.754 & 0.552 & & \\
\hline & \multirow{4}{*}{ Total } & Intervention & $2.39 \pm 3.9$ & $1.92 \pm 4.0$ & -0.47 & $0.022^{*}$ \\
\hline & & Control & $2.20 \pm 3.4$ & $1.98 \pm 4.0$ & -0.22 & 0.138 \\
\hline & & Between group difference & 0.19 & -0.06 & -0.25 & \\
\hline & & $p$-value ${ }^{3)}$ & 0.514 & 0.588 & & \\
\hline \multirow{4}{*}{\multicolumn{2}{|c|}{$\begin{array}{l}\text { Absence/ early leave/ tardiness } \\
\text { due to health problem }\end{array}$}} & Intervention & $0.89 \pm 1.8$ & $0.57 \pm 1.6$ & -0.32 & $0.044^{*}$ \\
\hline & & Control & $0.69 \pm 1.6$ & $0.69 \pm 2.0$ & 0.00 & 0.517 \\
\hline & & Between group difference & 0.20 & -0.12 & -0.32 & \\
\hline & & $p$-value ${ }^{3)}$ & 0.993 & 0.896 & & \\
\hline
\end{tabular}

1) Value are presented as mean $\pm S D$

2) $p$-value by Wilcoxon singed rank test. $<0.05$

3) $p$-value by Mann-Whitney $U$ test. $<0.05$ 
before and after intervention

Table 5 shows the difference in before and after intervention of the number of medical use and absence, early leave, and tardiness of participating children.

Regarding medical use due to digestive diseases, the Wilcoxon signed rank test of the intervention group showed statistically significant results $(p=0.010)$, and also showed statistical significance in the Mann-Whitney $\mathrm{U}$ test $(p=0.005)$. Regarding medical use due to otolaryngology related diseases, statistical significance was shown in the Wilcoxon signed rank test for the control group. In the overall medical use for respiratory, digestive, and otolaryngology diseases, statistical significance was shown in the intervention group after the Wilcoxon signed rank test $(p=0.044)$.

3) Difference in difference analysis result using zero inflated negative binomial regression

The results of difference in difference analysis using zero inflated negative binomial regression model of the participating children follows table 6 . Regarding the net effect of the difference in difference related variables regarding digestive diseases, both group difference variable and time difference variable did not show statistically significant results but with the result of -0.137 for the group difference variable and -0.388 for the time difference variable, both results showed decreases in

Table 6. Difference in Difference Analysis using by Zero Inflated Negative Binomial Regression

\begin{tabular}{|c|c|c|c|c|c|c|c|c|c|c|c|c|}
\hline \multirow{3}{*}{ Variables } & \multicolumn{9}{|c|}{ Medical Utilization } & \multirow{2}{*}{\multicolumn{2}{|c|}{$\begin{array}{c}\text { Absence, early leave, } \\
\text { tardiness due to } \\
\text { health problem } \\
\end{array}$}} & \multirow{3}{*}{$p$-value } \\
\hline & \multicolumn{2}{|c|}{ Respiratory } & \multicolumn{2}{|c|}{ Digestive } & \multicolumn{2}{|c|}{ Otolaryngology } & \multicolumn{2}{|c|}{ Total } & \multirow{2}{*}{$p$-value } & & & \\
\hline & $\beta$ & S.E & $\beta$ & S.E & $\beta$ & S.E & $\beta$ & S.E & & $\beta$ & S.E & \\
\hline \multicolumn{13}{|l|}{ group \# time ${ }^{1)}$} \\
\hline 10 & 0.472 & 0.096 & -0.137 & 0.470 & 0.258 & 0.302 & 0.085 & 0.133 & 0.524 & -0.364 & 0.172 & $0.035^{*}$ \\
\hline 01 & -0.016 & 0.134 & -0.388 & 0.473 & -0.398 & 0.310 & -0.105 & 0.134 & 0.433 & -0.008 & 0.240 & 0.974 \\
\hline 11 & -0.140 & 0.190 & $-1.649^{*}$ & 0.767 & 0.241 & 0.430 & -0.114 & 0.189 & 0.545 & -0.302 & 0.339 & 0.373 \\
\hline
\end{tabular}

Table 7. Difference in Difference Analysis Using by Zero Inflated Negative Binomial Regression (Include control variables)

\begin{tabular}{|c|c|c|c|c|c|c|}
\hline \multirow{3}{*}{ Variables } & \multicolumn{3}{|c|}{ Medical Utilization } & \multirow{2}{*}{\multicolumn{2}{|c|}{$\begin{array}{l}\text { Absence, early leave, tardiness } \\
\text { due to health problem }\end{array}$}} & \multirow{3}{*}{$p$-value } \\
\hline & \multicolumn{2}{|c|}{ Total } & \multirow{2}{*}{$p$-value } & & & \\
\hline & $\beta$ & S.E & & $\beta$ & S.E & \\
\hline \multicolumn{7}{|l|}{ group \# time } \\
\hline 10 & 0.061 & 0.140 & 0.661 & 0.097 & 0.251 & 0.698 \\
\hline 01 & -0.120 & 0.143 & 0.400 & -0.244 & 0.261 & 0.349 \\
\hline 11 & -0.084 & 0.197 & 0.670 & -0.013 & 0.357 & 0.971 \\
\hline \multicolumn{7}{|l|}{ control variables } \\
\hline sex (ref =boy) & -0.230 & 0.100 & $0.022^{*}$ & 0.005 & 0.185 & 0.979 \\
\hline age (ref $=4$ yrs old or older) & 0.172 & 0.099 & 0.083 & 0.113 & 0.181 & 0.532 \\
\hline sibling (ref $=$ have sibling) & -0.210 & 0.127 & 0.099 & -0.302 & 0.233 & 0.195 \\
\hline care of mother (ref $=$ care of mother) & -0.129 & 0.168 & 0.441 & -0.043 & 0.311 & 0.891 \\
\hline Monthly income (ref $=4$ million won or more) & -0.185 & 0.101 & 0.067 & -0.264 & 0.192 & 0.168 \\
\hline education level of mother (ref=College or higher) & 0.406 & 0.137 & $0.003 *$ & 0.757 & 0.255 & $0.003 *$ \\
\hline
\end{tabular}


medical use. The difference in difference effect showed statistically significant results $(\beta=-1.649$, $p<0.05$ ), and it also showed decreases in medical use after intervention.

4) Difference in difference analysis result using zero inflated negative binomial regression model including control variables

The difference in difference analysis result using zero inflated negative binomial regression model including control variables follow table 7. The gender and final level of education of mother showed statistically significant results and the number of hospitalization days tend to increase when the mother's final education level was higher than high school than below. The number of hospitalization days decreased in the case of female than male. Although it wasn't statistically significant, the number of hospitalization days decreased (table 7) for time variables, mutual intersectional articles, when the children had siblings, when nurtured by mother most of the time, and when income was higher than $\$ 4000$ than below. Regarding the number of absence, early leave and tardiness, when the mother's final education level was higher than high school education, the number of medical utilization increased more than the level being below high school education and when the child was a girl than a boy. Although it wasn't statistically significant, the number of medical utilization decreased for time variables, mutual intersectional articles, when the children had siblings, when nurtured by mother most of the time, and when income was higher than $\$ 4000$ than below. When applying control variables that can influence medical utilization along with difference in difference related variables, the gender $(p=0.022)$ and mother's level of education $(p=0.003)$ was shown to be statistically significant.

The number of medical utilization decreased more for girls than boys $(\beta=-0.230)$, and when the mother had higher education levels, the number of medical utilization increased $(\beta=0.406)$. When applying the control variables that can influence the number of absence, early leave and tardiness along with difference in difference related variables, the mother's education level was the only variable that showed statistical significance $(\mathrm{p}=0.003)$, and it was evident that the higher the education level, the greater the number of medical use $(\beta=0.757)$.

\section{Further Consideration}

The following study put 268 participants in the intervention group and 277 in the controlled group. The participants were children between the ages of 2 and 6 from 6 different child care centers at Wonju, Gangwon-do Province and Chungju, Chungcheongbuk-do Province. The effects of the Korean medical health promotion program on children were evaluated after 6 weeks of the program, and the program was different for children, parents, and teachers. 268 participants were in the intervention group and 277 were in the controlled group for 6 weeks. Children and parents in the intervention group were put in prevention programs (common cold prevention scarf, growth exercises and herbal pear snacks), child education, and parent education. No programs were provided for the controlled group.

After investigating the overall number of medical use and change in number of absence, early leave and tardiness before and after the Korean medical health promotion program on children, although there were no significance in the matching sample t-test and linear regression analysis, it could be seen that the number of medical use due to overall illness (respiratory, digestive and otolaryngology related diseases) and the number of absence, early leave and tardiness due to illness reduced more in the intervention group than the controlled group. The difference in difference analysis utilizing the negative binomial regression model on the participating children proved that net effects of the 
difference in difference related variables indicated that the number of medical use due to illness and total number of absence, early leave and tardiness tend to reduce. The difference in difference effect indicated statistically significant results $(\beta=-1.649$, $p<0.05$ ) and showed the number of medical use decreasing after intervention. The reason why it wasn't statistically significant at first was thought to be due to the short demonstration program period of 6 weeks, which isn't enough to apply the health condition and life style of program participants.

When looking at preceding research conducted by Park et $\mathrm{al}^{22,23)}$, where the medical use, absence and leave, attitude of the teacher regarding the illness due to infectious diseases was measured before and after the program of having a Korean medical doctor at child care institutions, the research and design was similar to the following study, and the results also showed similar outcomes of the total number of medical use of children not showing statistically significant results but showed reduction in medical use. In a different preceding research ${ }^{24}$ which focused on Korean medical house doctor programs on vulnerable children, the difference in difference analysis did not show statistically significant results but showed patterns of reduction in the number of medical use, and days of absence, early leave and tardiness, drawing similar conclusions. In the previous two preceding researches, under the research model of Korean medical family doctors of health promotion programs for children, there were drug interventions. However, the following research did not have any sort of drug interventions and still drew out similar conclusions, overall indicating greater significance.

Statistical significance varied in the category of nutrition and health for each control variables. These included the number of children, health condition of children and final education level of mother ${ }^{25}$. The results showed similar results to preceding studies which signified the higher the education level of mother, the greater in levels of knowledge of nutrition and health. The results also corresponded to those of Kim et $\mathrm{al}^{26}$, which indicated that less number of children signifies greater knowledge in child care diseases. Also, differences were shown depending on the occupation of mother which showed similar results to the preceding study that proved the higher the education level and younger the age, the more positive effects on the health promotion $^{27)}$.

The importance and demand of education for parents and teachers which has a direct impact on the children are being emphasized. According to preceding research findings on parent education, only $14.3 \%$ had experience of participating in educational sessions which therefore indicate the necessity and demand for parent education and signifies that parents are wanting to receive professional and trust-worthy education from institutions that have public confidence ${ }^{28,29)}$. As the social demand for child care facilities to maintain the health of children are becoming higher ${ }^{30)}$, regular health evaluation is crucial and various education methods including building more knowledge to understand the child's health, and looking back at life style habits are being requested $^{31)}$. Furthermore, demand in strengthening the education program for teachers to maintain the child's health better, development and supply of standardized manual, building local health centers and child care centers together, and systematic support from health professionals were high ${ }^{32}$.

In terms of the health knowledge and act after the program, attitude towards infections, knowledge in Korean medical health and act of Korean medical health habits were higher in the intervention group than the controlled group. 6 weeks after the program ended, the study investigated how often the growth exercise and common cold prevention scarf was used by teachers. In order to test the participants' willingness, the after investigation was not mentioned and there were no demands or restrictions 
either. For each category, most of the participants continued the growth exercise at least once a week, and for the common cold prevention scarf, the highest number of participants of 15 participants (35.7\%) were using it 3-4 times a week. The two programs were conducted as the survey results showed significant results. $78.6 \%$ were conducting the growth exercise with their free will and $90.5 \%$ of the participants used the common cold prevention scar once a week.

\section{Limitations}

As the number of medical use was a variable that completely depended on the memory of parents, it was difficult to exclude the possibility of information bias regarding the memory, and although there were methods such as confirming the information of medical treatment from the Health Insurance Review and Assessment Service, there were limitations in agreement of personal information and therefore could not be applied in this study.

The following study was conducted by a health promotion program based on curing methods of Korean Medicine and therefore effective intervention Korean medical treatments such as acupuncture, moxibustion, and medicine were not applied. As a result, limitations of not being able to see dramatic effectiveness remained. Furthermore, as the measure for evaluating the effectiveness was mostly based on surveys, development in measuring index that can appropriately indicate the effectiveness at the time is fundamental.

Overall, the analysis results showed that the number of medical use and absence, early leave tardiness due to sickness tend to reduce in the intervention group compared to the control group for overall diseases (respiratory, digestive, and otolaryngology related). In the satisfactory survey conducted after the program, both the participation and satisfactory level were high in children's education and parent education.

\section{Summary and Conclusion}

The effects of the Korean Medicine Health Promotion program for children between 2 and 6 , conducted with Korean medicine intervention (child education, parents education, common cold prevention scarf, growth exercises and pear herbal tea) was analyzed and the results follow the below.

1. Although the matching sample $t$ test on the medical use before and after the program did not show significant results, compared to the controlled group, the number of medical use, absence, early leave and tardiness due to overall illness (respiratory, digestive, and otolaryngology) reduced more in the intervention group.

2. In the non-parametric statistical analysis for medical use, the number of medical utilization due to digestive diseases decreased significantly in the intervention group $(\mathrm{p}=0.010, \mathrm{p}=0.05)$, and the Wilcoxon signed rank test for the intervention group showed statistically significant lower results for medical utilization due to overall diseases (respiratory, digestive, otolaryngology) $(\mathrm{p}=0.044)$ and in the number of absence, early leave and tardiness $(\mathrm{p}=0.044)$

3. The difference in difference analysis result using zero inflated negative binomial regression model on the participating children did not show statistically significant results in both the group difference variable and time variable in the net effects of the variables related to digestive diseases, however with a figure of -0.137 in the group difference variable and -0.388 in the time variable, it could be seen that the medical use did tend to decrease. The difference in difference effect did show statistically significant results $(\beta=-1.649$, $p<0.05$ ), with medical utilization decreasing after the intervention.

4. The difference in difference analysis results 
using zero inflated negative binomial regression model including control variables showed that the gender $(\mathrm{p}=0.022)$ and education level of mother $(\mathrm{p}=0.003)$ were the variables that showed statistical significant. The medical use decreased more with girls than boys $(\beta=-0.230)$, and it was shown that the number of the medical use increased if the mother had higher education levels $(\beta=0.406)$. When applying control variables that can have an effect on the absence, early leave and tardiness along with the difference in difference related variables, the education level of the mother $(\mathrm{p}=0.003)$ was shown to be the variable that is statistically significant, and the higher the education level of the mother, the more utilization of medical use $(\beta=0.757)$.

Overall when applying the Korean medicine health promotion program for children between 2 and 6 , conducted with health interventions, the program did contribute towards increasing the level of health as the number of medical use and absence, early leave, and tardiness due to illness did decrease. Furthermore, the program passed on correct information on Korean medicine to both the parents and children and through educating them on how to maintain good health based on Korean medicine, the program encouraged durability and demand for future programs like the above.

\section{References}

1. Kim SH. A study on the knowledge and the actual condition of management for early childhood diseases of mothers and child care teachers[master's thesis]. Ulsan: Ulsan Univ.; 2011.

2. Cho YH. The mutual relationship and the level of the day-care center teacher and the mother about the eating habits, the nutritional knowledge and the nutritional attitude[master's thesis]. Seoul: Sungshin Women's Univ.; 2011.

3. Kim IO, Kim YH, Park JS, Kim SJ, Oh SE,
Chang GJ, et al. Effect of the early childhood health care education program for parents in child care centers. J Korean Public Health Nursing. 2011;25(1):84-94.

4. Choi NY, Jeon MY, Seo HM, Seok JW, Kim MS, Jeong HC. Development and evaluation of a combined health promotion program for preschool children. J Korean Acad Child Health Nurs. 2010;16(4):314-323.

5. Lee SJ, Han DW, Yoon TH, Song KM, Kim YS. Perception of health center staff on health promotion programme using traditional Korean Medicine. J Korean Oriental Med. 2007;28(3): 1-12.

6. Ministry of Health and Welfare. Development of Korean Medicine health promotion program and study on linkage with community. 2014.

7. Lee EK, Chong MS, Lee KN. Considerations on a support system for Oriental medicine public health programs. Kor. J. Oriental preventive medicine society. 2011;15(3):1-16.

8. Choi KJ, Kim HJ, Ahn SW. A Research on the improvement measures about Community-based Korean medical public health service in public service center. Korean Journal of Oriental Medicine. 2004;10(1):107-117.

9. Korean Institute of Oriental Medicine. 2013 Year Book of Traditional Korean Medicine. 2013.

10. Ministry of Health and Welfare. 2012 Public health guide in Korean Medicine. 2012.

11. Ministry of Health and Welfare. 2016 Introduction of community health promotion in Korean Medicine. Korea Health Promotion Institute. 2016.

12. CHO JK. Life cycle Korean Medicine health promotion project status and future plans. Society of Preventive Korean Medicine Spring Conference. 2017.

13. Korean Institute of Oriental Medicine. 2015 Year Book of Traditional Korean Medicine. 
2015

14. Kim HS, Lee CY, Lee TW, Ham OK. Health problems and health behaviors of preschoolers. Korean society of nursing science 2004;34(1): 182-190.

15. Kim HS. Development of Health Promotion Programs for Preschoolers in Health Centers Connected to Day-care Centers . Korean Society for Health Education and Promotion. 2005: 155-179.

16. Shin HS. Needs assessment and program development of child health. Ministry of Health and Welfare. 2009.

17. Lee YM. The different view point of child education center food service program between the parents and the teachers. Korean J Community Nutrition. 2005;10(5):654-667.

18. Kim SJ, Yang SO, Lee SH, Lee JE, Kim SH, Kang KA. Development and evaluation of a child health care protocal for child day care center teachers. J Korean Acad child health Nurs. 2011;17(1):74-83.

19. Choi KJ, Jeong HS. Impacts of the benefit extension policy on financial burden and catastrophic health care expenditure. The Korean Journal of Health Economics and Policy. 2012;18(4):1-19.

20. Min KC. The Difference-in-Difference Model Analysis about the Effects of Long-Term Care Insurance on Family Relationships' Change. Journal of the Korean Gerontological Society. 2011;31(4):999-1014.

21. Lee JH, Moon SH. The effect of basic pension on the income of elderly people - Analysis using Propensity Score Matching (PSM) Difference In Differences (DID)-.The Korea Association for Policy Studies. 2014;23(3): 411-440

22. Park JM. Development and evaluation of comprehensive health care program in child care centers by Korean medical doctor[master's thesis]. Seoul: Seoul National Univ.; 2013.

23. Park JM, Park MJ, Cho BH. Development and Evaluation of Comprehensive Health Care Program for Infectious Disease Management in Child Care Centers by Doctor of Korean Medicine. Korean J Health Educ Promot. 2013;30(1):65-81.

24. Ministry of Health and Welfare. Development of Health Promotion System for Vulnerable Children using Korean Medicine. 2016.

25. Kim HS, Ra JS. Health Management Status of Day Care Centers. 2008;14(3):295-304.

26. Baek HC. Comparative Study on Health Promoting Behavior in Working and Non-working Mothers with Infants and Toddlers. J Korean Acad Community Health Nurs. 2014;25(4): 282-290.

27. Kim SJ, Kang KA, Yun J, Kwon OJ. Development of a tool to measure health promotion behavior for infants \& toddlers. J Korean Acad Child Health Nurs. 2007;13(1): 21-32.

28. Kim IO, Kang RY. A survey on the health examination of child care centers. J Korean Acad Child Health Nurs. 2005;11(3):308-315.

29. Seo HM, Jeon MY, Choi NY. Health knowledge, health guidance execution and health education needs of parents of preschoolers. $\mathrm{J}$ of Korean academy of public health nursing. 2009;23(2): 207-218.

30. Yun SY. Comparison of fathers' and mothers' participation and needs assessment on the parent education of their young children[master's thesis]. Seoul: Ewha Womans Univ.; 2003.

31. Min SY, Kim JH. A survey on recognition about oriental child care and Oriental Medicine in parents attending in oriental child care class in health center. J Korena oriental pediatrics. 2011;25(3):35-45.

32. Kim SJ, Lee JE, Yang SO, Kang KA, CHang EY, Oh KS, et al. Perception of child day care 
center teachers on issues and needs in child

Nurs. 2011;17(1):10-21.

health management. J Korean Acad Child Health 